\title{
Acute Respiratory Distress Syndrome Due to Gobar Gas-An Unintended Occupational Hazard!!
}

\section{Shetti NA*, Singla B and Lendal SP \\ Department of Anesthesiology and Critical Care, Rural Medical College, India}

*Corresponding author: Dr. Akshaya N Shetti, Professor, Department of Anesthesiology and Critical Care, Rural Medical College, Maharashtra, India, Tel: +917507807673; Email: aksnsdr@gmail.com

\section{Case Report \\ Volume 4 Issue 3}

Received Date: August 18, 2019

Published Date: September 10, 2019

DOI: $10.23880 /$ accmj-16000158

\section{Abstract}

The gobar gas is a biogas with various advantages to common man especially in a developing country. It reduces the pollution, fuel import bill, prevents deforestations and improves living standards in rural areas. Unfortunately, there are occupation related injuries which are seen with gobar gas plant. The gas has highest concentration of methane (50-75\%), which may cause life threatening problems like acute toxic pneumonitis when inhaled. Here, we report a case of accidental occupational injury due to gobar gas to a 35 year old male patient and its successful management in the intensive care unit.

Keywords: Acute respiratory distress; Methane; Occupational hazard

\section{Introduction}

In rural India, the gobar gas is more popular due to various advantages like it is free, easily maintained, all agriculture related wastes especially the cow dung can be easily dumped in to it. One of the components of the gobar gas is methane [1]. The methane is a harmless gas but due to high concentration in a closed chamber, the oxygen content in the chamber reduces drastically, causing difficulty in breathing and hypoxia related injury in an individual. Here we report a case of acute pulmonary toxicity due to inhalation of methane gas while cleaning the gobar gas chamber and presented with acute respiratory failure.

\section{Case report}

A 35-year-old male patient was brought to the casualty department with history of unconsciousness. The history stated that the patient was made to clean the gobar gas tank. When the patient entered the tank, by about five minutes there was no response from him as per the co-worker. The co-worker suspected something wrong and could identify this person was not responding. The person was almost 10 minutes inside the tank and reached the hospital by about 2 hours after exposure. On examination, patient was drowsy but he was responding to painful stimulus and the clothing's were soiled with vomitus. Examination of respiratory system revealed 


\section{Anaesthesia \& Critical Care Medicine Journal}

equal bilateral air entry but with basal crepitation's (more on right side compared with left).

The patient's vitals in the casualty were; blood pressure of $130 / 80 \mathrm{~mm} \mathrm{Hg}$, Heart rate of $108 / \mathrm{min}$, oxygen saturation of $88 \%$ with room air and on supplemental oxygen $(10 \mathrm{~L} / \mathrm{min})$ by mask it raised to $98 \%$, respiratory rate of $25 / \mathrm{min}$ and temperature of $37.2^{\circ} \mathrm{C}$. The arterial blood gas (ABG) at the time of admission showed $\mathrm{pH}-7.3, \mathrm{pCO}_{2}-32 \mathrm{~mm} \mathrm{Hg}, \mathrm{pO}_{2}-145$ $\mathrm{mm} \mathrm{Hg}, \mathrm{HCO}_{3}-15.7 \mathrm{mmol} / \mathrm{L}$, and $\mathrm{SaO} 2$ - 99\% suggestive of mild metabolic acidosis. Other blood investigations like complete blood count, renal and liver function tests showed no abnormalities. The electrocardiogram showed mild tachycardia, regular rhythm suggestive of sinus tachycardia. The chest radiograph showed bilateral opacities (ground glass appearance) more on right side in perihilar region (Figure 1). The cardiac and great vessel shadows appeared normal. The patient received Inj Piperacillin tazobactum $4.5 \mathrm{gm}$ thrice a day and Inj Levofloxacin $800 \mathrm{mg}$ twice a day as per institutional policy.

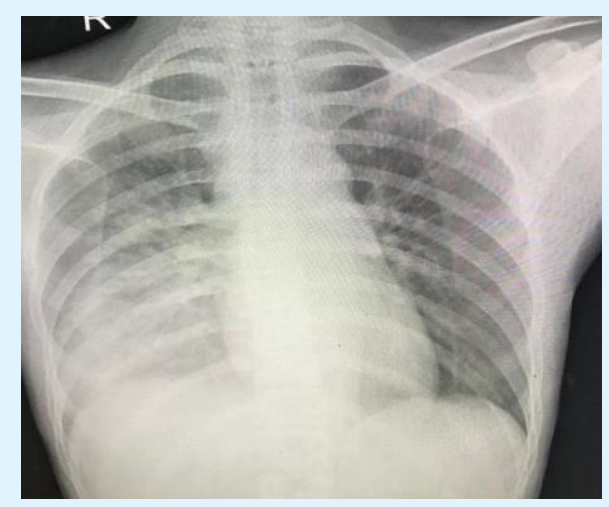

Figure 1: Chest radiograph on admission day (day 1).

The patient was shifted to intensive care unit (ICU) from casualty unit for further management. After 4 hours of ICU admission, the patient's respiratory rate increased to $40 / \mathrm{min}$ and oxygen saturation started falling. The noninvasive mechanical ventilation was used to overcome this but failed to maintain the oxygen saturation even after giving fractional inspired oxygen concentration $\left(\mathrm{FiO}_{2}\right)$ of 1 . A decision was made for invasive mechanical ventilation. With this, the oxygen saturation improved to $100 \%$ (with $\mathrm{FiO}_{2}$ of 1 ). The further $\mathrm{ABGs}$ showed improvement in partial pressure of oxygen and further reduction of $\mathrm{FiO}_{2}$ was made till 0.3 . The bicarbonate and partial pressure of carbon dioxide became normal. Patient was weaned from the mechanical ventilation as per institutional protocol.

The chest radiograph improved on day 3 (Figure 2), which showed near normal lung fields. The patient was extubated after successful spontaneous breathing trial. Patient was shifted from the intensive care unit to the step down unit and got discharged from the hospital on 5th day of admission.

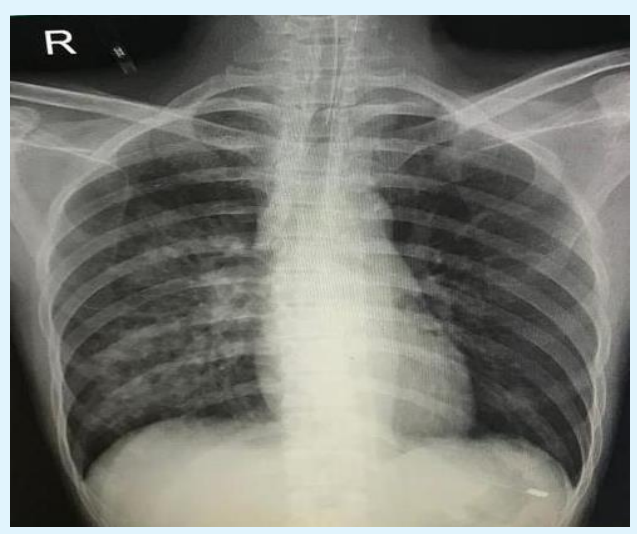

Figure 2: Chest radiograph on day 3 (Bilaterally reduces haziness)

\section{Discussion}

The gobar gas is also known as biogas, dung gas, sewage gas and swamp gas. The typical composition of the gas is methane $(50-75 \%)$, carbon dioxide $(25-50 \%)$, Nitrogen (0-10\%), Hydrogen (0-1\%), hydrogen sulfide $(0.1-0.5 \%)$ and oxygen $(0-0.5 \%)$. Methane is most abundant organic gas in the atmosphere. Various occupational injuries are recorded till date [2,3]. Methane is biologically inert and it has been shown that exposure to methane at $10,000 \mathrm{ppm}$ had no toxic effect [4-6].

The methane gas inhalation causes asphyxia like situation in the tank as the percentage of the oxygen in the tank is nearly $0-0.5 \%$. This is one of the reasons why the person becomes unconscious. The unpleasant odor may be the reason for the nausea and vomiting. The combination of unconsciousness and vomiting may become life threatening as the aspiration chances are very high and patient may die due to acute lung injury or acute respiratory distress syndrome. It has been documented in the previous reports that even a one minute exposure to high concentration methane in a closed room will cause loss of consciousness. 


\section{Anaesthesia \& Critical Care Medicine Journal}

The author Jun Yeon Jo, et al. describes that person who gets exposed to high concentration to methane will have restrictive ventilator defect [1]. Though there is no known exact pathology of methane toxicity on lungs, author predicts the methane intoxication may cause reversible toxic alveolitis. In our case, we assumed that pathology of lung may be due to combination of aspiration and methane toxicity. We could not do CT thorax and pulmonary function test due to nonaffordability of the patient. The recent research on methane gas suggests that when inhaled along with oxygen rich air, it has an anti-inflammatory, antioxidant property and anti-apoptosis features. In rodents $21 \% 02$ $+2.5 \%$ methane has proved its safety [7].

\section{Conclusion}

Preventive measures by education and regular health check of sewage and sanitary workers should be made mandatory and one should replace the manual techniques. Immediate supportive measures and early recognition and treating complications due to methane toxicity may improve the outcome.

\section{References}

1. Jo JY, Kwon YS, Lee JW, Park JS, Rho BH, et al. (2013) Acute respiratory distress due to methane inhalation. Tuberc Respir Dis (Seoul) 74(3): 120-123.
2. Tatic V, Stankovic Z, Hadzic Z (1991) Morphologic damage in internal organs in miners caused by explosions of methane gas in mines. Vojnosanit Pregl 48(6): 547-550.

3. Li Z, Jia Y, Feng Y, Cui R, Miao R, et al (2019) Methane alleviates sepsis-induced injury by inhibiting pyroptosis and apoptosis: in vivo and in vitro experiments. Aging (Albany NY) 11(4): 1226-1239.

4. Kamens RM, Stern AC (1973) Methane in air quality and automobile exhaust emission standards. J Air Pollut Control Assoc 23(7): 592-596.

5. National Research Council (US) Committee on Toxicology (1984) METHANE. In: Emergency and Continuous Exposure Limits for Selected Airborne Contaminants (Volume 1), National Academy Press Washington, DC: 95-98. https://www.ncbi.nlm.nih.gov/books/NBK208284/

6. Tiwari RR (2008) Occupational health hazards in sewage and sanitary workers. Indian J Occup Environ Med 12(3): 112-115.

7. Jia Y, Li Z, Liu C, Zhang J (2018) Methane Medicine: A Rising Star Gas with Powerful Anti-Inflammation, Antioxidant, and Antiapoptosis Properties. Oxid Med Cell Longev (8): 1-10. 